\title{
Arecoline induces dual modulation of blood pressure in rat, including an initial downregulation and a subsequent upregulation
}

\author{
Jiashan Wu, Lijuan Chen, Meiping Deng, Xiaowen Ye, Xiaoxia Jiang, Jiangliu \\ Fu, Peiling Zhou, Changzheng Zhang* \\ Guangdong Provincial Key Laboratory of Development and Education for Special Needs Children \& School of Educational \\ Sciences, Lingnan Normal University, Zhanjiang 524048, China
}

*For correspondence: Email: neurobiologyzhang@yahoo.com; Tel: +86-15261879383

Sent for review: 24 March 2020

Revised accepted: 26 July 2020

\begin{abstract}
Purpose: To determine the role of arecoline in cardiovascular modulation in rats. Methods: After rats were anaesthetized with intraperitoneal urethane (1.4 g/kg body weight), saline or arecoline (at doses of 1.0, 3.0 and $10.0 \mathrm{mg} / \mathrm{kg}$ ) was intraperitoneally administered, and blood pressure $(B P)$ was continuously recorded using a physiological apparatus. Mean arterial pressure (MAP), maximum changes in MAP and reaction time due to arecoline stimulations were calculated and analyzed.

Results: Arecoline induced biphasic modulation in BP, including an initial downregulation followed by a subsequent upregulation. The MAP and maximum change in MAP exhibited a concentration-dependent effect in the downregulation phase $(p<0.001$ within each group), but not in the upregulation phase $(p>$ 0.05 within each group), while $B P$ reaction time showed a dose-dependent prolongation in both downregulation and upregulation phases ( $p s<0.01$ within each group). Remarkably, arecoline-induced $B P$ downregulation more rapidly and drastically than upregulation in each arecoline group.

Conclusion: These results indicate that arecoline exerts a complex effect in cardiovascular modulation that should be considered as side effects in the clinical use of arecoline and/or with the habitual chewing of areca nuts.
\end{abstract}

Keywords: Arecoline, Blood pressure, Downregulation, Upregulation

\begin{abstract}
This is an Open Access article that uses a fund-ing model which does not charge readers or their institutions for access and distributed under the terms of the Creative Commons Attribution License (http://creativecommons.org/licenses/by/4.0) and the Budapest Open Access Initiative (http://www.budapestopenaccessinitiative.org/read), which permit unrestricted use, distribution, and reproduction in any medium, provided the original work is properly credited.

Tropical Journal of Pharmaceutical Research is indexed by Science Citation Index (SciSearch), Scopus, International Pharmaceutical Abstract, Chemical Abstracts, Embase, Index Copernicus, EBSCO, African Index Medicus, JournalSeek, Journal Citation Reports/Science Edition, Directory of Open Access Journals (DOAJ), African Journal Online, Bioline International, Open-J-Gate and Pharmacy Abstracts
\end{abstract}

\section{INTRODUCTION}

Areca (betel) nuts are the fruits of the Areca catechu palm tree, which are endemic to South and Southeast Asia (especially in China, India, Indonesia, Malaysia, Philippines, and New Guinea). Areca nuts are mainly used for chewing, which is reported to cause relaxation, evoke euphoria, and enhance postprandial satisfaction $[1,2]$. It is estimated that more than 600 million people frequently chew areca nuts, making it the fourth most widely-used psychoactive substance in the world, after alcohol, tobacco, and caffeine [1,3,4]. Many studies have demonstrated that areca nut 
chewing causes dependency syndrome and withdrawal syndrome, resulting in emotional fluctuations, agrypnia, anxiety and irritability [3]. Nevertheless, areca nuts are a popular herbal medicine that has long been used in clinical practice, such as the treatment of parasitic diseases, digestive disorders, and inflammation [1].

Arecoline is the main bioactive alkaloid in areca nuts, and it has several pharmacological effects that are parasympathetic in nature [5]. Arecoline has frequently been reported to exhibit beneficial effects in patients with Alzheimer dementia (AD), schizophrenia, and depression [6-9]. Because of the parasympathetic features, arecoline also causes cardiovascular modulations, but with contradictory effects. For example, many studies recorded that chewing areca nuts raised the risk of cardiovascular disorders [10-13], while other studies reported that arecoline decreased or increased blood pressure (BP) and heart rate [14-16]. Also, other studies found that arecoline failed to exert a significant effect altogether on BP [9].

The present study aimed to explore whether and how arecoline modulated $\mathrm{BP}$, to provide a reference for clinical practice and a perspective for preclinical investigations on the pharmacological and toxicological characteristics of arecoline, or areca nuts in general.

\section{EXPERIMENTAL}

\section{Animals}

Healthy adult male Sprague-Dawley rats (2 months old, $240 \pm 20 \mathrm{~g} ; n=17$ ) were purchased from Jinan Pengyue Experimental Animal Breeding Co. LTD (Jinan, China). The animals were housed in a temperature-controlled $(25 \pm 1$ ${ }^{\circ} \mathrm{C}$ ) environment with a $12 \mathrm{~h}$ light/12-h dark cycle and ad libitum feed and water. All animal experiments abided by the rules of the National Institutes of Health Guide for the Care and Use of Laboratory Animals (NIH Publication No. 8023, revised in 1996), and were approved by the Academic and Ethics Committee of Lingnan Normal University.

\section{Surgical procedures}

Blood pressure recordings followed the procedure used in previous reports $[17,18]$. The rats were anesthetized with intraperitoneal urethane (1.4 g/kg body weight; Sinopharm Chemical Reagent Co. Ltd., Shanghai, China), followed by cervical surgery and tracheal intubation. Then, a catheter was inserted into the right carotid artery and connected to a physiological apparatus (BL-420F, Taimeng Technology Co. Ltd., Chengdu, China) for BP signal collecting and processing.

\section{BP measurement}

Rats were maintained in the ventral decubitus position for BP recordings. Once the BP was stable, saline $(0.9 \% \mathrm{NaCl})$ or arecoline (at a dose of 1.0, 3.0 and 10.0 $\mathrm{mg} / \mathrm{kg} / 1.0 \mathrm{~mL}$ ) was separately injected ( 10 s) into the abdominal cavity. The effects of arecoline on BP regulations were regarded as substance-specific if they were reversible and reproducible.

Repeated injections were administered at intervals of 60 min to avoid the drug interference between administrations [19]. In general, each rat was given 4 - 6 injections with different drugs, and those that did not return to the basal level (i.e., those that deviated over $10 \%$ from the pretest levels) were excluded from further analyses.

Arecoline induced biphasic modulations in the BP (an initial downregulation, followed by a subsequent upregulation). The reaction times of $\mathrm{BP}$ responses to arecoline stimulations (including period 1 for the BP downregulation phase, and period 2 for the BP upregulation phase), mean arterial pressure (MAP) during period 1 and period 2, the maximum change in MAP, including MDMAP (maximum decreased MAP) and MIMAP (maximum increased MAP) during each arecoline trial were calculated. Since no alterations in BP were observed upon saline treatment, the MAPs in period 1 and period 2 for the saline treatment were calculated from two 60sec BP sequences beginning at $10 \mathrm{sec}$ and 100 sec, respectively.

\section{Statistical analysis}

All data are presented as mean \pm standard error of the mean (SEM). A one-way analysis of variance (ANOVA) followed by a Fisher's least significant difference post hoc test were conducted for statistical analyses. $P<0.05$ was considered statistically significant.

\section{RESULTS}

Compared to the saline treatment group (Figure 1 A), arecoline treatment induced biphasic modulations in the BPs of the rats, i.e., an initial downregulation followed by a subsequent upregulation (Figure $1 \mathrm{~B}$ - D).

Trop J Pharm Res, August 2020; 19(8): 1638 

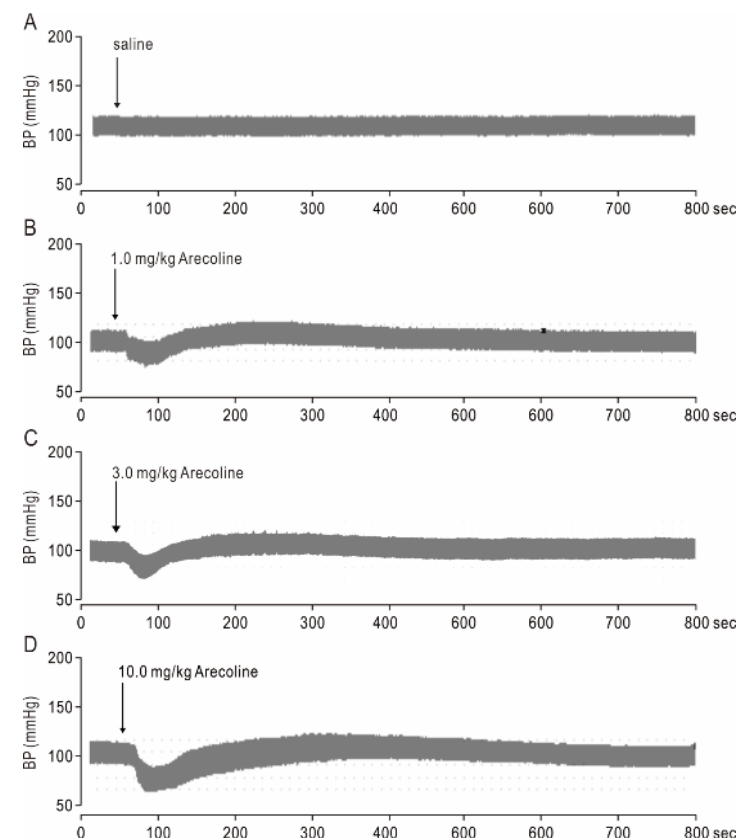

Figure 1: Representative blood pressure recordings following intraperitoneal injections of arecoline. A: Injection of saline induced no obvious changes in BP. B-D: Injection of $1.0,3.0$ and $10.0 \mathrm{mg} / \mathrm{kg}$ arecoline, respectively, induced biphasic modulations in BP. The arrows indicate the time of injection. BP: blood pressure

\section{Arecoline induced MAP alterations}

The values of the MAPs showed no significant differences among groups before treatments (saline, $102.96 \pm 2.17 \mathrm{mmHg} ; 1.0 \mathrm{mg} / \mathrm{kg}, 108.64$ $\pm 1.91 \mathrm{mmHg} ; 3.0 \mathrm{mg} / \mathrm{kg}, 104.4 \pm 1.52 \mathrm{mmHg}$; $10.0 \mathrm{mg} / \mathrm{kg}, 108.91 \pm 3.45 \mathrm{mmHg} ; \mathrm{F} 3,34=$ 1.777, $P=0.170$; Figure 2). Compared to saline administration, arecoline treatment decreased the MAPs of rats in period 1 (saline, $102.8 \pm 2.03$ $\mathrm{mmHg} ; 1.0 \mathrm{mg} / \mathrm{kg}, 96.68 \pm 2.19 \mathrm{mmHg} ; 3.0$ $\mathrm{mg} / \mathrm{kg}, 90.39 \pm 2.74 \mathrm{mmHg} ; 10.0 \mathrm{mg} / \mathrm{kg} .87 .26 \pm$ $2.37 \mathrm{mmHg}$; F3,34 = 8.371, $P<0.001$; Figure 2), and increased MAPs in period 2 (saline, $103.58 \pm$ $2.02 \mathrm{mmHg} ; 1.0 \mathrm{mg} / \mathrm{kg}, 116.44 \pm 1.42 \mathrm{mmHg}$; $3.0 \mathrm{mg} / \mathrm{kg}, 111.86 \pm 2.04 \mathrm{mmHg} ; 10.0 \mathrm{mg} / \mathrm{kg}$, $116.81 \pm 3.34 \mathrm{mmHg} ; \mathrm{F} 3,34=7.986, P<0.001$; Figure 2).

\section{Arecoline induced maximum changes in MAP}

Post hoc analyses indicated that the MDMAP in period 1 were significantly different among different arecoline treatments (F2,25 $=13.302, p$ $<0.001$; Figure 3). Remarkably, the MDMAP in the $10.0 \mathrm{mg} / \mathrm{kg}$ arecoline-treatment group increased by $101.27 \%$ compared to that of the $1.0 \mathrm{mg} / \mathrm{kg}$ treatment $(p<0.001$; Figure 3$)$. Post hoc analyses also revealed that MIMAP in in period $2(\mathrm{~F} 2,25=0.358, p=0.703$; Figure 3$)$, was not significantly different among arecoline treatments.

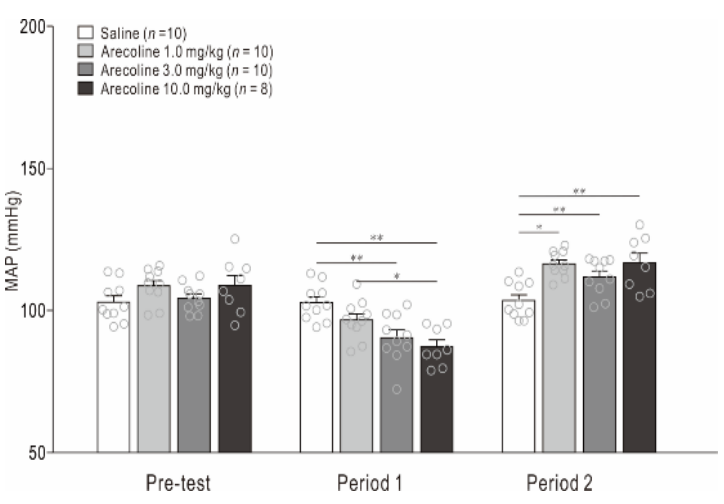

Figure 2: Histogram of arecoline-mediated effects on mean arterial pressure (MAP). Pre-test: Prior to drug treatment; period 1: the duration of $\mathrm{BP}$ downregulation; period 2: the duration of $\mathrm{BP}$ upregulation. The numbers in parentheses represent the measurements in each group; ${ }^{*} p<0.05,{ }^{* *} p<0.01$

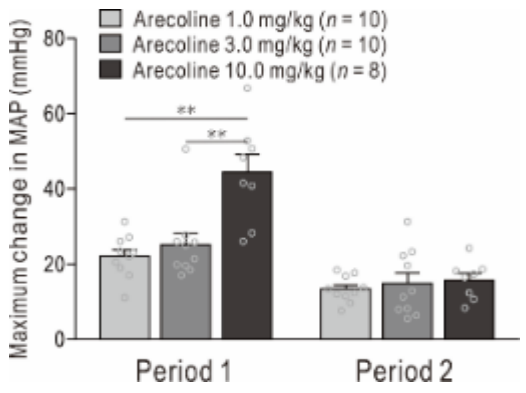

Figure 3: Arecoline-mediated effect on maximum changes in MAP (including maximum decrease in MAP in period 1 and maximum increase in MAP in period 2 ); ${ }^{*} p<0.05,{ }^{* *} p<0.01$

\section{Reaction time of arecoline-induced BP modulations}

The BP reaction time due to arecoline treatment was also significantly different between groups in period $1(\mathrm{~F} 2,25=47.889, p<0.001$, Figure 4; in which the reaction time was prolonged by $123.15 \%$ in the $10.0 \mathrm{mg} / \mathrm{kg}$ arecoline-treatment group compared to that in the $1.0 \mathrm{mg} / \mathrm{kg}$ treatment group) and in period 2 (F2,25 $=6.375$, $p=0.006$, Figure 4 ; in which the reaction time was prolonged by $78.97 \%$ in the $10.0 \mathrm{mg} / \mathrm{kg}$ arecoline-treatment group compared to the 1.0 $\mathrm{mg} / \mathrm{kg}$ treatment group).

\section{BP downregulation and upregulation due to arecoline stimulations}

The arecoline-induced BP downregulations were of higher magnitude (1-3 fold in MDMAP vs. MIMAP) than the upregulations. 
Table 1: Downregulation and the upregulation due to arecoline-mediated BP modulations

\begin{tabular}{lccc}
\hline Parameter & \multicolumn{3}{c}{ Downregulation/upregulation } \\
\cline { 2 - 4 } & $\mathbf{1 . 0} \mathbf{~} \mathbf{g} / \mathbf{k g}$ & $\mathbf{3 . 0} \mathbf{~ m g / k g}$ & $\mathbf{1 0 . 0} \mathbf{~} \mathbf{g} / \mathbf{k g}$ \\
\hline Maximum changes in MAP $(\mathrm{mmHg})$ & 1.65 & 1.69 & 2.81 \\
Reaction time $(\mathrm{s})$ & 0.21 & 0.21 & 0.26 \\
\hline
\end{tabular}

However, the durations of downregulation were longer ( $\sim 5$ fold in period 2 vs. period 1$)$ than those of the upregulation (Table 1). Thus, those data indicated the intense, but transient downregulation relative to the upregulation in response to arecoline treatments.

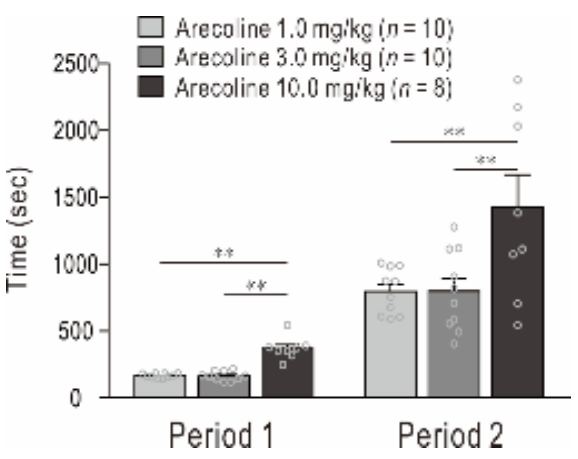

Figure 4: Histograms of arecoline-mediated effects on the BP reaction time (including period 1 and period 2) in response to arecoline stimulations. BP: blood pressure; ${ }^{*} p<0.05,{ }^{* *} p<0.01$

\section{DISCUSSION}

Arecoline has long been known to exhibit multiple cholinomimetic effects that are predominantly parasympathetic in nature. Such effects have frequently been studied in animal models and observed in clinical settings, including effects on stress reduction, cardiovascular modulation, digestive promotion, and endocrine functions [5-8,20,21]. However, relatively little is known about how arecoline regulates BP. This study reported that arecoline evoked biphasic modulations on the BPs of rats, with an initial downregulation in BP, followed by a subsequent upregulation.

The BP changes induced by arecoline (1.0, 3.0 and $10.0 \mathrm{mg} / \mathrm{kg}$ ) generally recovered within 800 sec (Figure 1), which was consistent with previous reports on arecoline action times in behavioral demonstrations [8] and metabolic examinations [4]. Arecoline-induced decreases in $\mathrm{BP}$ may be due to arecoline-mediated relaxation of the aorta endothelium and/or improvement of vasorelaxation [2]. However, arecoline-mediated BP upregulations cannot be explained merely by the cholinergic effect. Notably, several lines of experimental evidence suggest that arecoline is excitatory to the hypothalamic-pituitary-adrenal
(HPA) axis and stimulates adrenocorticotropic hormone release [22]. Therefore, it is hypothesized that arecoline-mediated upregulation of BP may be due to the activation of the HPA axis. However, the precise mechanisms leading to the biphasic regulations in $\mathrm{BPs}$ require further investigations.

\section{CONCLUSION}

Given that arecoline or areca nuts are frequently used as therapeutic substances for various ailments, the findings of this study suggest that the cardiovascular effects of such treatments be taken into consideration during clinical use.

\section{DECLARATIONS}

\section{Acknowledgement}

This work was supported by grants from the National Natural Science Foundation of China (no. 81871062), the National Natural Science Foundation of Guangdong Province (no. 2019A1515010331), Natural Science Foundation of Guangdong Provincial Education Bureau (no. 2017KTSCX117), and the Special Foundation for Talents of Lingnan Normal University (no. ZL1819).

\section{Conflict of interest}

No conflict of interest is associated with this work.

\section{Contribution of authors}

We declare that this work was done by the authors named in this article and all liabilities pertaining to claims relating to the content of this article will be borne by the authors. Changzheng Zhang and Peiling Zhou designed the experiments and wrote the paper. Jiashan $\mathrm{Wu}$, Lijuan Chen, Meiping Deng, Xiaowen Ye, Xiaoxia Jiang and Jiangliu $\mathrm{Fu}$ performed the experiments. Jiashan $\mathrm{Wu}$ and Lijuan Chen analyzed the data.

\section{Open Access}

This is an Open Access article that uses a funding model which does not charge readers or their 
institutions for access and distributed under the terms of the Creative Commons Attribution License (http://creativecommons.org/licenses/by/ 4.0) and the Budapest Open Access Initiative (http://www.budapestopenaccessinitiative.org/rea d), which permit unrestricted use, distribution, and reproduction in any medium, provided the original work is properly credited.

\section{REFERENCES}

1. Peng $W$, LiU $Y J, W u N$, Sun $T, H e X Y, G a o Y X, W u C J$. Areca catechu L. (Arecaceae): A review of its traditional uses, botany, phytochemistry, pharmacology and toxicology. J Ethnopharmacol 2015; 164: 340-356.

2. Liu YJ, Peng $W, H u M B, X u M, W u \quad C J$. The pharmacology, toxicology and potential applications of arecoline: a review. Pharm Biol 2016; 54: 1-8.

3. Volgin A, Bashirzade A, Amstislavskaya $T$, Yakovlev $O$, Demin K, Ho Y-J, Wang D, Shevyrin VA, Yan D, Tang Z, et al. DARK Classics in Chemical Neuroscience: Arecoline. ACS Chem Neurosci 2019; 10: 2176-2185.

4. Sarbani G, Idle JR, Chi C, T Mark Z, Krausz KW, Gonzalez FJ. A metabolomic approach to the metabolism of the areca nut alkaloids arecoline and arecaidine in the mouse. Chem Res Toxicol 2006; 19: 818-827.

5. Pan H, Huang L, Li Y, Zhou X, Lu Y, Shi F. Liquid chromatography-tandem mass spectrometric assay for determination of unstable arecoline in rat plasma and its application. J Chromatogr B Analyt Technol Biomed Life Sci 2017; 1070: 112-116.

6. Christie JE, Shering A, Ferguson J, Glen Al. Physostigmine and arecoline: effects of intravenous infusions in Alzheimer presenile dementia. $\mathrm{Br} \mathrm{J}$ Psychiatry 1981; 138: 46-50.

7. Xu Z, Adilijiang A, Wang W, You P, Lin D, Li X, He J. Arecoline attenuates memory impairment and demyelination in a cuprizone-induced mouse model of schizophrenia. Neuroreport 2019; 30: 134-138.

8. Dasgupta R, Saha I, Maity A, Ray PP, Maiti BR. Arecoline ameliorates hyperthyroid condition in mice under cold stress. Arch Physiol Biochem 2018; 124: 436-441.

9. Pomara $N$, Stanley $M$, Lewitt $P A$, Galloway $M$, Singh $R$, Deptula D. Increased CSF HVA response to arecoline challenge in Alzheimer's disease. J Neural Transm 1992; 90: 53-65.
10. Zhang LN, Yang YM, Xu ZR, Gui QF, Hu QQ. Chewing substances with or without tobacco and risk of cardiovascular disease in Asia: a meta-analysis. J Zhejiang Univ Sci B 2010; 11: 681-689.

11. Chiou SS, Kuo CD. Effect of chewing a single betel-quid on autonomic nervous modulation in healthy young adults. J Psychopharmacol 2008; 22: 910-917.

12. Choudhury MD, Chetia $P$, Choudhury KD, Talukdar $A D$, Datta-Choudhari M. Atherogenic effect of Arecoline: $A$ computational study. Bioinformation 2012; 8: 229-232.

13. Thakur N, Sharma AK, Singh H, Mehrotra R. ANDB: Development of a database based on a global survey of literature on Areca nut and associated health effects. Subst Use Misuse 2019: 1-6.

14. Barnes JC, Roberts FF. Central effects of muscarinic agonists and antagonists on hippocampal theta rhythm and blood pressure in the anaesthetised rat. Eur $\mathrm{J}$ Pharmacol 1991; 195: 233-240.

15. Chu N, Shin. Neurological aspects of areca and betel chewing. Addict Biol 2002; 7: 111-114.

16. Dahl RE, Ryan ND, Perel J, Birmaher B, Puig-Antich J. Cholinergic REM induction test with arecoline in depressed children. Psychiat Res 1994; 51: 269-282.

17. Zhu Q, Zhou P, Wang S, Zhang C, Hua T. A preliminary study on cerebellar acetylcholine-mediated blood pressure regulation in young and old rats. Exp Gerontol 2015; 63: 76-80.

18. Zhou P, Zhu Q, Liu M, Li J, Wang Y, Zhang C, Hua T. Muscarinic acetylcholine receptor in cerebellar cortex participates in acetylcholine-mediated blood depressor response in rats. Neurosci Lett 2015; 593: 129-133.

19. Zhang $C$, Luo $W$, Zhou $P$, Sun T. Microinjection of acetylcholine into cerebellar fastigial nucleus induces blood depressor response in anesthetized rats. Neurosci Lett 2016; 629: 79-84.

20. Bales A, Peterson MJ, Ojha S, Upadhaya K, Adhikari B, Barrett B. Associations between betel nut (Areca catechu) and symptoms of schizophrenia among patients in Nepal: A longitudinal study. Psychiat Res 2009; 169: 203-211.

21. Dasgupta R, Saha I, Pal S, Bhattacharyya A, Sa G, Nag TC, Das T, Maiti BR. Immunosuppression, hepatotoxicity and depression of antioxidant status by arecoline in albino mice. Toxicol 2006; 227: 94-104.

22. Calogero AE, Kamilaris TC, Gomez MT, Johnson EO, Tartaglia ME, Gold PW, Chrousos GP. The muscarinic cholinergic agonist arecoline stimulates the rat hypothalamic-pituitary-adrenal axis through a centrallymediated corticotropin-releasing hormone-dependent mechanism. Endocrinol 1989; 125: 2445-2453.

Trop J Pharm Res, August 2020; 19(8): 1641 